EGU21-10671

https://doi.org/10.5194/egusphere-egu21-10671

EGU General Assembly 2021

(c) Author(s) 2021. This work is distributed under

the Creative Commons Attribution 4.0 License.

\title{
A review of worldwide sediment core dating research including fallout radiocaesium (137Cs)
}

\author{
Anthony Foucher ${ }^{1}$, Pierre Sabatier ${ }^{2}$, Pierre-Alexis Chaboche ${ }^{1}$, and Olivier Evrard ${ }^{1}$ \\ ${ }^{1}$ Laboratoire des Sciences du Climat et de l'Environnement (LSCE/IPSL), Université Paris-Saclay, UMR 8212 (CEA-CNRS- \\ UVSQ), Gif-sur-Yvette, France (anthony.foucher@outlook.com) \\ ${ }^{2}$ EDYTEM, Université Savoie-Mont Blanc, Université Grenoble Alpes, CNRS, 73370, Le Bourget du Lac, France
}

Dating recent sediment archives ( $<150$ years) constitutes are need for environmental and climatic reconstructions. Radiocaesium $\left({ }^{137} \mathrm{Cs}\right)$ emitted during thermonuclear bombs testing ( 1950 1980) and nuclear accidents (1986 and 2011) was generally used for identifying sediment sources or for establishing sediment core chronology based on discrete time markers. Although this method was widely used during the last several decades, there is a lack of structured and comprehensive worldwide synthesis of radiocaesium fallouts. The current literature overview was based on 573 articles published between 1977 and 2020, reporting the collection of 1351 individual dated sediment cores. This synthesis led to the identification of the worldwide distribution of discrete time markers associated with the thermonuclear bomb testing peak in 1963, the Chernobyl fallout, the Fukushima fallout, as well as the identification of at least 25 events induced by local accidents or nuclear tests (e.g. Sellafield, la Hague accidents, Chinese nuclear tests).

With a growing number of studies focusing on the analysis of recent sediment cores and the increasing interest in sediment fingerprinting techniques, this spatialized synthesis provides a unique worldwide referential for identifying the distribution of the ${ }^{137} \mathrm{Cs}$ sources at global scale. It also outlines the main questions that would deserve attention in future research perspectives and the regions where ${ }^{137} \mathrm{Cs}$ fallouts investigations should be conducted in priority. 